\title{
Dye Sensitized Solar Cells Based on Hydrazonoyl Synthetic Dyes
}

\author{
Monzir S. Abdel-Latif ${ }^{1,2}$, Amal Batniji ${ }^{2,3}$, Taher M. El-Agez ${ }^{2,3}$, Malak J. Younis's,3, Hatem Ghamri ${ }^{2,3}$, \\ Bassam A. Abu Thaher ${ }^{1}$, Basem S. Qeshta ${ }^{1}$, Fakhr M. Abu-Awwad ${ }^{1}$, Sofyan A. Taya ${ }^{2,3, *}$ \\ 1 Chemistry Department, Islamic University of Gaza, Gaza, Palestine \\ 2 Renewable Energy Center, Islamic University of Gaza, Gaza, Palestine \\ ${ }^{3}$ Physics Department, Islamic University of Gaza, Gaza, Palestine
}

(Received 16 May 2016; published online 29 November 2016)

\begin{abstract}
A group of chemical sensitizers of two hydrazonoyl based derivatives were synthesized. These derivatives contain a good $\pi$ system for efficient light absorption and oxide sensitization. Precursor structure I was reacted with 2,6-diaminopyridine, 2-aminobenzoic acid, 4-aminobenzoic acid, 2-aminopyridine, 2,6-dinitrophenylhydrazine, and diphenylamine. The other precursor, structure (II), was reacted with 2-aminobenzoic acid, 2-amino-3-methyl, and 2-amino-4-methylpyridine. A total of 9 dyes were prepared and evaluated as sensitizers for dye-sensitized solar cells (DSSCs). Full computational calculations using DFT B3LYP 6-31+G were carried out for evaluation of band edge and band gap energies of all compounds. The absorption spectra of these dyes as well as cyclic voltammetry were used for the measurement of the HOMO, LUMO, and energy band gaps. The photovoltaic performance of the fabricated DSSCs was measured in different solutions comprising water, alcohol, phenylhydrazine, and dinitrophenylhydazine.
\end{abstract}

Keywords: Dye-sensitized solar cells, Synthetic dyes, Quantum mechanical calculations, Band gap energies.

DOI: 10.21272/jnep.8(4(1)).04038

PACS numbers: 88.40.H -

\section{INTRODUCTION}

A solar cell collects solar energy and converts it into electrical/chemical energy. It works similarly to a plant leaf. Dye-sensitized solar cell (DSSC), as one of the most recent solar cells, was firstly developed by Grätzel's group [1-3]. It has many advantages over other solar energy conversion technologies because of its simple construction and inexpensive materials. Moreover, the color of the device can be easily varied by choosing different synthetic or natural dyes. DSSCs on flexible substrates have been already demonstrated. DSSCs are especially attractive for building integrated photovoltaics. Therefore, DSSCs have been intensively studied as a new type of solar cells, which are composed of nanocrystalline porous semiconductor electrode, dye adsorbed on the semiconductor nanopowder, a counter electrode and an electrolyte of iodidetriiodide ions. The dye plays a crucial role in absorbing visible light and converting photon energy into electricity. Much attention has been paid to survey the effective sensitizer dyes [4]. Synthetic [5-8] and natural [9-17] dyes have been widely investigated as photosensitizers for DSSCs. $\mathrm{TiO}_{2}$ has been widely studied for efficient DSSCs. With $\mathrm{TiO}_{2}$-based dye-sensitized solar cells, efficiencies of up to $11 \%$ have been obtained using standard ruthenium polypyridyl complexes as a sensitizer in the laboratory conditions [1]. In the following, some significant works employing synthetic dyes are presented.

Echeverry et al. studied the synthesis and characterization of five new organic dyes based on 2-(1,1dicyanomethylene) rhodanine [18]. The dye containing two (1,1dicyanomethylene)rhodanine units and no thiophene units showed the best photovoltaic performance with an overall conversion efficiency of $3.78 \%$. Chen et al. studied the synthesis and characterization of the photoelectrochemical characteristics of a ruthenium photosensitizer with an alkyl bithiophene group, designated as CYC-B1 [19]. The effect of mesoporous $\mathrm{TiO}_{2}$ film thickness on the photovoltaic performance of CYCB1 and N3 dye-sensitized solar cells was investigated. Five aldimine derivatives were prepared by condensation of the appropriate amine with salicylaldehyde [6]. These derivatives were used as photosensitizers for DSSCs. A novel and efficient polyene-diphenylaniline dye for dye sensitized solar cells has been synthesized [20]. The dye has a short synthesis route and is readily adsorbed on $\mathrm{TiO}_{2}$ under a variety of dye-bath conditions.

In this work, DSSCs were fabricated using $\mathrm{TiO}_{2}$ nanoparticles as a semiconducting layer and two groups of synthetic photosensitizers based on derivatives of structures I and II (Fig. 1). These dyes were characterized by UV-VIS spectrophotometry, Kubla-Munk and CV (HOMO - LUMO) analysis, as well as theoretical quantum mechanical calculations. The photovoltaic properties of the fabricated DSSCs were investigated.

\section{EXPERIMENT}

\subsection{Preparation of the Dyes}

A group of synthetic sensitizers based on derivatives of structures I and II shown in Fig. 1 was synthesized. Some of these derivatives have one or two carboxylate anchoring groups that are reported to strongly bind to $\mathrm{TiO}_{2}$ and facilitate electron transfer. In addition, they contain a good $\Pi$ system for efficient light absorption and oxide sensitization

Precursor structure I was reacted with 2,6diaminopyridine, 2-aminobenzoic acid, 4-aminobenzoic acid, 2-aminopyridine, 2,6-dinitrophenylhydrazine, and diphenylamine. While precursor structure II was reacted with 2-aminobenzoic acid, 2-amino-3-methyl, and 2-amino-4-methylpyridine. A total of nine dyes were

\footnotetext{
* staya@iugaza.edu.ps
} 
prepared and evaluated as sensitizers. These dyes are designated as: $\mathrm{Hy}-\mathrm{COOH}-2-\mathrm{AP}$ (A), Hy-2,6-DAP (B), Hy-COOH-DPA (C), Hy-COOH-4-ABA (D), Hy-2,4DNPH (E), Hy-COOH-2-ABA (F), Hy-Cl-4-Pic (G), HyCl-3-Pic (H), and Ac-2-ABA (I). These dyes will be labeled as A, B, C, ... as can be seen in Table 1 .

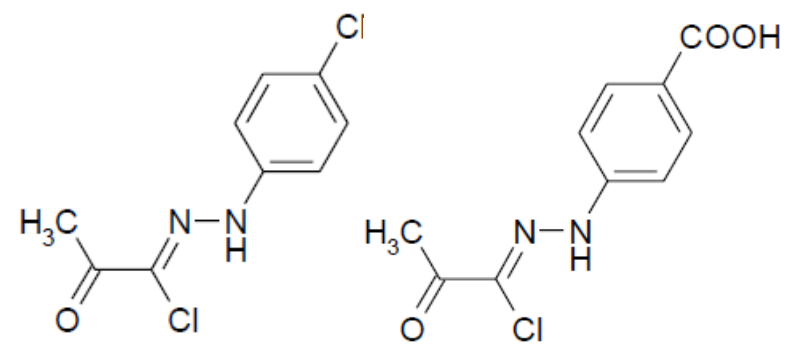

Fig. 1-Molecular structures of the precursor compounds used in this work

Compounds A, C, D, F, and I were prepared by transferring triethylamine $(0.006 \mathrm{~mol})$ in dry THF $(10$ $\mathrm{ml}$ ), which was dropwise added to a stirred solution of hydrazonoyl chlorides $(0.005 \mathrm{~mol})$ and the appropriate derivative $(0.006 \mathrm{~mol})$ in $25 \mathrm{ml} \mathrm{THF}$ at room temperature, producing the respective derivatives. Stirring was continued overnight, and the solvent was then evaporated in vacuum. Water was added to the residual solid, and the mixture was acidified slightly by adding few drops of acetic acid, and then filtrated. The crude products were then recrystallized from hot ethanol to give the title compounds.

Compounds B, G, H were prepared by the same procedure above by using the appropriate derivative producing the respective compounds. The residual solid obtained after evaporating the solvent was washed with water to remove the triethylamonium salt. The crude products were then recrystallized from hot ethanol to give the title compounds.

Compound $\mathrm{E}$ was prepared by heating the solution containing hydrazonoyl chloride, 2,4-dinitrophenylhydrazine, and few drops of sulfuric acid. The reaction was followed by TLC. The solvent was minimized and the solid filtrated. The crude product was recrystallized from hot ethanol

Table 1 - Structures and abbreviations of synthesized compounds<smiles>Cc1nc2ccccn2c1/N=N/c1ccc(C(=O)O)cc1</smiles>

(E)-4-((2-methylimidazo[1,2-a]pyridin-3-yl)diazenyl)benzoic acid A. $\mathrm{Hy}-\mathrm{COOH}-2-\mathrm{AP}$<smiles>CC(=O)/C(=N/Nc1ccc(C(=O)O)cc1)N(c1ccccc1)c1ccccc1</smiles>

(Z)-4-(2-(1-(diphenylamino)-2-oxopropylidene)hydrazinyl)benzoic acid

\section{Hy-COOH-DPA}<smiles>C/C(=N\Nc1ccc([N+](=O)[O-])cc1[N+](=O)[O-])C(Cl)=NNc1ccc(Cl)cc1</smiles>

(1Z,2E)-N'-(4-chlorophenyl)-2-(2-(2,4-dinitrophenyl)hydrazono)propanehydrazonoyl chloride<smiles>Cc1nc2cccc(N)n2c1/N=N/c1ccc(Cl)cc1</smiles>

$(E)$-3-((4-chlorophenyl)diazenyl)-2-methylimidazo[1,2-a]pyridin-5-amine B. Hy-2,6-DAP<smiles>CC(=O)C(=NNc1ccc(C(=O)O)cc1)Nc1ccc(C(=O)O)cc1</smiles>

(Z)-4-(N'-(4-carboxyphenyl)-2-oxopropylhydrazonamido)benzoic acid

D. $\mathrm{Hy}-\mathrm{COOH}-4-\mathrm{ABA}$<smiles>CC(=O)/C(=N/Nc1ccc(C(=O)O)cc1)Nc1ccccc1C(=O)O</smiles>

(Z)-2-( $N$ '-(4-carboxyphenyl)-2-oxopropylhydrazonamido)benzoic acid

F. Hy-COOH-2-ABA 
<smiles>Cc1ccn2c(/N=N/c3ccc(Cl)cc3)c(C)nc2c1</smiles>

(E)-3-((4-chlorophenyl)diazenyl)-2,7dimethylimidazo[1,2- $a]$ pyridine

G. Hy-Cl-4-pic<smiles>CC(=O)/C(=N/Nc1ccc(Cl)cc1)Nc1ccccc1C(=O)O</smiles>

(Z)-2-(N'-(4-chlorophenyl)-2-oxopropylhydrazonamido)benzoic acid I. Ac-2-ABA

\subsection{Assembly of DSSCs}

$\mathrm{TiO}_{2}$ paste was prepared by blending $50 \mathrm{mg}$ of $\mathrm{TiO}_{2}$ nanopowder and $100 \mathrm{mg}$ of polyethylene glycol in an agate mortar. The mixture was grinded for $30 \mathrm{~min}$ until a homogeneous paste was obtained. The $\mathrm{TiO}_{2}$ paste was obtained. The $\mathrm{TiO}_{2}$ paste was then applied to Fluorine doped tin oxide (FTO) coated transparent conducting glass substrate (resistance $10-15 \mathrm{ohm} \cdot \mathrm{cm}^{-2}$ ) which was cut into pieces of dimensions $1.5 \mathrm{~cm} \times 1.5 \mathrm{~cm}$ and cleaned with detergent solution using an ultrasonic bath for $20 \mathrm{~min}$, rinsed with water and Ethanol and then dried. By Doctor Blade method, an approximately $10 \mu \mathrm{m}$ thick $\mathrm{TiO}_{2}$ film of area $0.25 \mathrm{~cm}^{2}$ was obtained. $\mathrm{TiO}_{2}$ films were heat treated at $70{ }^{\circ} \mathrm{C}$ for 20 min to dry them and then sintered at $450{ }^{\circ} \mathrm{C}$ for $40 \mathrm{~min}$ and cooled down to $70{ }^{\circ} \mathrm{C}$. They were immersed separately in the chemical dye solutions for 24 hours in the dark. For each of the previously mentioned dyes, five different solutions were obtained as follows:

- $0.02 \mathrm{mg}$ of dry compound was added to $10 \mathrm{ml}$ of water.

- $0.02 \mathrm{mg}$ of dry compound was added to $10 \mathrm{ml}$ of alcohol and $0.02 \mathrm{mg}$ of phenylhydrazine (M.W. 144.60 gm mol).

- $0.02 \mathrm{mg}$ of dry compound was added to $10 \mathrm{ml}$ of water and $0.02 \mathrm{mg}$ of phenylhydrazine (M.W. 144.60 $\mathrm{gm} / \mathrm{mol})$.

- $0.02 \mathrm{mg}$ of dry compound was added to $10 \mathrm{ml}$ of alcohol and $0.02 \mathrm{mg}$ of 2,4- dinitrophenylhydazine (M.W. $198.14 \mathrm{gm} / \mathrm{mol}$ ).

- $0.02 \mathrm{mg}$ of dry compound was added to $10 \mathrm{ml}$ of water and $0.02 \mathrm{mg}$ of 2,4- dinitrophenylhydazine (M.W. $198.14 \mathrm{gm} / \mathrm{mol})$.<smiles>Cc1nc2c(C)cccn2c1/N=N/c1ccc(Cl)cc1</smiles>

H. Hy-Cl-3-pic

\subsection{Characterization and Measurement}

The absorption spectra measurements of the dyes in ethyl alcohol solution were performed using a UV-VIS spectrophotometer (Thermoline Genesys 6). The wavelength range of absorption spectral analysis was measured from 300-900 nm. The CV (HOMO-LUMO) measurements for each dye were performed using an Autolab potentiostat, and the $J-V$ Characteristics of the fabricated solar cells at an illumination of $100 \mathrm{~mW} \cdot \mathrm{cm}^{-2}$ were measured using National Instruments data acquisition card (USB NI 6251) with a Labview program via computer controlled software. High pressure mercury lamp was used to obtain a simulated sunlight with an intensity of $100 \mathrm{~mW} \cdot \mathrm{cm}^{-2}$. The fill factor $(F F)$ defined as

$$
F F=\frac{I_{m p} \cdot V_{m p}}{I_{s c} \cdot V_{o c}}
$$

was calculated from the $J-V$ curve of each cell, where $I_{m p}$ and $V_{m p}$ are the photocurrent and photovoltage of the maximum power output $\left(P_{\max }\right), I_{s c}$ and $V_{o c}$ are the short circuit photocurrent and open circuit photovoltage, respectively. The energy conversion efficiency $(\eta)$ is defined as follows

$$
\eta=\frac{F F \cdot I_{s c} \cdot V_{o c}}{P_{i n}}
$$

where $P_{\text {in }}$ is the input power.

\section{RESULTS AND DISCUSSIONS}

\subsection{Characterization of the Synthesized Dyes}


The structures of the prepared dyes was confirmed using conventional analytical techniques, including FTIR (KBr), NMR (300 MHz, DMSO-d6), as well as mass spectrometry.

\section{Complete analytical data for compound G}

3-[(4-Chlorophenyl)diazenyl]-2,7dimethylimidazo[1,2-a]pyridine 7 Yield $78 \%$, Yellow solid, mp $174{ }^{\circ} \mathrm{C}-177^{\circ} \mathrm{C}$; FTIR (KBr): $\underline{v m a x} \mathrm{~cm}^{-1}=$ 2993, 1520, 1473, 1462 and $796 \mathrm{~cm}^{-1} ; \mathrm{MS}: \mathrm{m} / \mathrm{z}$ C15H13ClN4 (284/286 M+ ., chlorine isotopes effect); HRMS (284.0902, Found 284.0901); 1 H NMR (300 MHz, DMSO-d6): $\delta 9.66(d, J=6.9 \mathrm{~Hz}, 1 \mathrm{H}), 7.88(d, J=$ $8.7 \mathrm{~Hz}, 2 \mathrm{H}), 7.59(d, J=8.8 \mathrm{~Hz}, 2 \mathrm{H}+1 \mathrm{H}$ pyr. $), 7.16(d$, $J=7.0 \mathrm{~Hz}, 1 \mathrm{H}), 2.71(s, 3 \mathrm{H}, \mathrm{CH} 3), 2.49(s, 3 \mathrm{H}, \mathrm{CH} 3)$; 13C NMR (100 MHz, DMSO-d6): $\delta$ 151, 149, 139, 136, $131,129,129,124,121,119,111,21,10$.

\section{Complete analytical data for compound $\mathrm{H}$}

3-[(4-Chlorophenyl)diazenyl]-2,8dimethylimidazo[1,2-a]pyridine 8 Yield $93 \%$, Yellow solid, mp $152^{\circ} \mathrm{C}-155^{\circ} \mathrm{C}$; FTIR (KBr): $\underline{v m a x} \mathrm{~cm}^{-1}=$ 1490, 1416, 1298, 1282, 1221, 1200, 1096, 811 and 774 $\mathrm{cm}^{-1}$. MS: m/z C15H13ClN4 (284/286 M+, chlorine isotope effect), HRMS (Calculated 284.0902, Found 284.0898). $1 \mathrm{H}$ NMR (300 MHz, DMSO-d6): $\delta 9.62(d, J$ $=7.0 \mathrm{~Hz}, 1 \mathrm{H}), 7.89(d, J=8.7 \mathrm{~Hz}, 2 \mathrm{H}), 7.60(d, J=8.7$ $\mathrm{Hz}, 2 \mathrm{H}), 7.51(d, J=7.0 \mathrm{~Hz}, 1 \mathrm{H}), 7.20(t, J=7.0 \mathrm{~Hz}$, $1 \mathrm{H}), 2.74(s, 3 \mathrm{H}, \mathrm{CH} 3), 2.58(s, 3 \mathrm{H}, \mathrm{CH} 3) .13 \mathrm{C} \mathrm{NMR}$ (100 MHz, DMSO-d6): $\delta$ 166.2, 151.4, 138.2, 136.1, $135.4,131.2,129.0,127.3,124.0,123.0,119.2,15.2$, 10.3.

\subsection{Cyclic Voltammetry and Absorption Spectra of Dyes}

Cyclic Voltammetry is one of the most common techniques used to characterize the redox properties of organic materials and estimate the energy band diagram. For organic semiconductors, highest occupied molecular orbital (HOMO) represents the energy required to extract an electron from a molecule, which is an oxidation process, and lowest unoccupied molecular orbital (LUMO) is the energy necessary to inject an electron to a molecule, thus implying a reduction process [21]. These processes can be measured using cyclic voltammetry by measuring the redox potentials $E_{o x}$ and $E_{r e d}$. The energy levels were calculated using the following empirical equations ( $\mathrm{Ag} / \mathrm{AgCl}$ reference electrode):

$$
E_{H O M O}=E_{o x}+4.4 \text { and } E_{L U M O}=E_{r e d}+4.4 .
$$

Figure 2 shows the current-voltage curves from the cyclic voltammetry (CV) measurements, absorption spectra and optical energy gap of three dyes: Hy-COOH-2-AP (A), Hy-COOH-2,6-DAP (B), HyCOOH-DPA (C). As shown in the figure, the corresponding wavelength to the band gap energy can be calculated from the cross point of absorption onset line and corrected base line.

The figures and calculations were conducted for the nine dyes listed in Table 1, and the HOMO and LUMO levels approximated for CV as well as the band gap and maximum absorption spectra for all dyes are shown in Table 2.

Figure 3 shows the band diagram with HOMO/ LUMO level of all dyes in addition to the FTO, redox and $\mathrm{Pt}$ work functions. The figure proves that the required energy level for the materials is fulfilled for fabricating solar cells using these dyes.

These dyes were used as photosensitizers for DSSCs. Diffuse reflectance spectra were collected with a V-670, JASCO spectrophotometer and transformed to the absorption spectra according to the Kubelka-Munk relationship. Figure 4 shows the absorption spectra of dye solutions of (A) Hy-COOH-2-AP, (B) Hy-2,6-DAP, and $(\mathrm{C}) \mathrm{Hy}-\mathrm{COOH}-\mathrm{DPA}$. The solid and dashed lines represent the absorption spectrum of the dye solution and that of the $\mathrm{TiO}_{2}$ electrode after being soaked in the dye solution. The absorption spectra of the three dyes in solutions show main peaks at the wavelengths given in Table 2. It can be observed that the absorption bands of dyes adsorbed on $\mathrm{TiO}_{2}$ film are red shifted towards higher wavelengths. These shifts towards lower energies can be attributed to complexation between the dyes and metal ions, $\mathrm{Ti}^{4+}$.

It is clear from Table 2 that quantum mechanical calculations of the HOMO-LUMO energies and band gaps of all compounds results in high values, although a good level of theory was used. Practically, the optical band gaps obtained from UV-Vis spectrophotometry were more appropriate, and reflects the actual colors of the different dyes. Therefore, it is suggested that theoretical calculations can be of real benefit in following the change in band edges upon using different substituents, rather than using absolute values of calculated energies.

\subsection{Photovoltaic Properties}

Nine synthetic photosensitizers (labeled as A, B, $\mathrm{C}, \ldots$ ets.) were used in manufacturing DSSCs. Each dye was used as a sensitizer in five different solutions labeled 1, 2, 3, 4, and 5 as follows:

- Using alcohol as a solvent with phenylhydrazine (MW = $144.60 \mathrm{gm} / \mathrm{mol})$,

- Using water as a solvent, no additives

- Using water as a solvent with phenylhydrazine $(\mathrm{MW}=144.60 \mathrm{gm} / \mathrm{mol})$,

- Using alcohol as a solvent with 2,4dinitrophenylhydazine ( $\mathrm{MW}=198.14 \mathrm{gm} / \mathrm{mol}$ ),

- Using water as a solvent with 2,4dinitrophenylhydazine ( $\mathrm{MW}=198.14 \mathrm{gm} / \mathrm{mol}$ ).

The J-V characteristic curves of the DSSCs were obtained through electrical current and voltage outputs under $100 \mathrm{~mW} / \mathrm{cm}^{2}$ illuminations. These curves are illustrated in figures 5, 6 and 7. Table 3 presents the photoelectrochemical parameters of the DSSCs sensitized with the three dyes A, B and C in the five different solutions. These parameters are short circuit current $J s c$, open circuit voltage $V o c$, and conversion efficiency $\eta$. From the table, dye A showed $J s c=0.1 \mathrm{~mA} / \mathrm{cm}^{2}, V o c=0.28 \mathrm{~V}$, and $\eta=0.01 \%$ in case of using water as a solvent. The same values of Jsc and $\eta$, and $V o c=0.307 \mathrm{~V}$ were obtained in case of using water with phenylhydrazine solution. Using alcohol as 

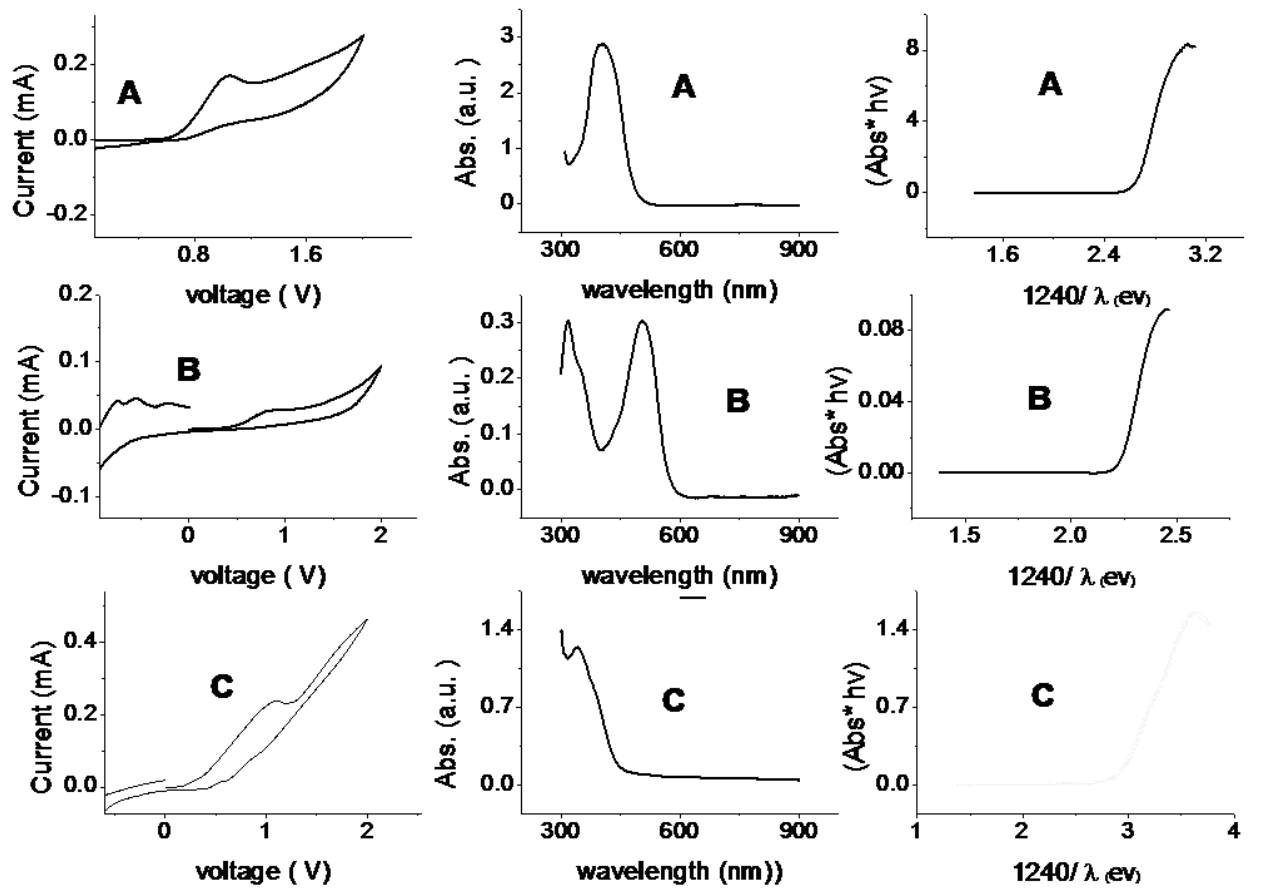

Fig. 2 - Current-voltage curve, absorption spectrum and optical band gap of Hy-COOH-2-AP (A), Hy-2,6-DAP (B), and Hy-COOHDPA (C)

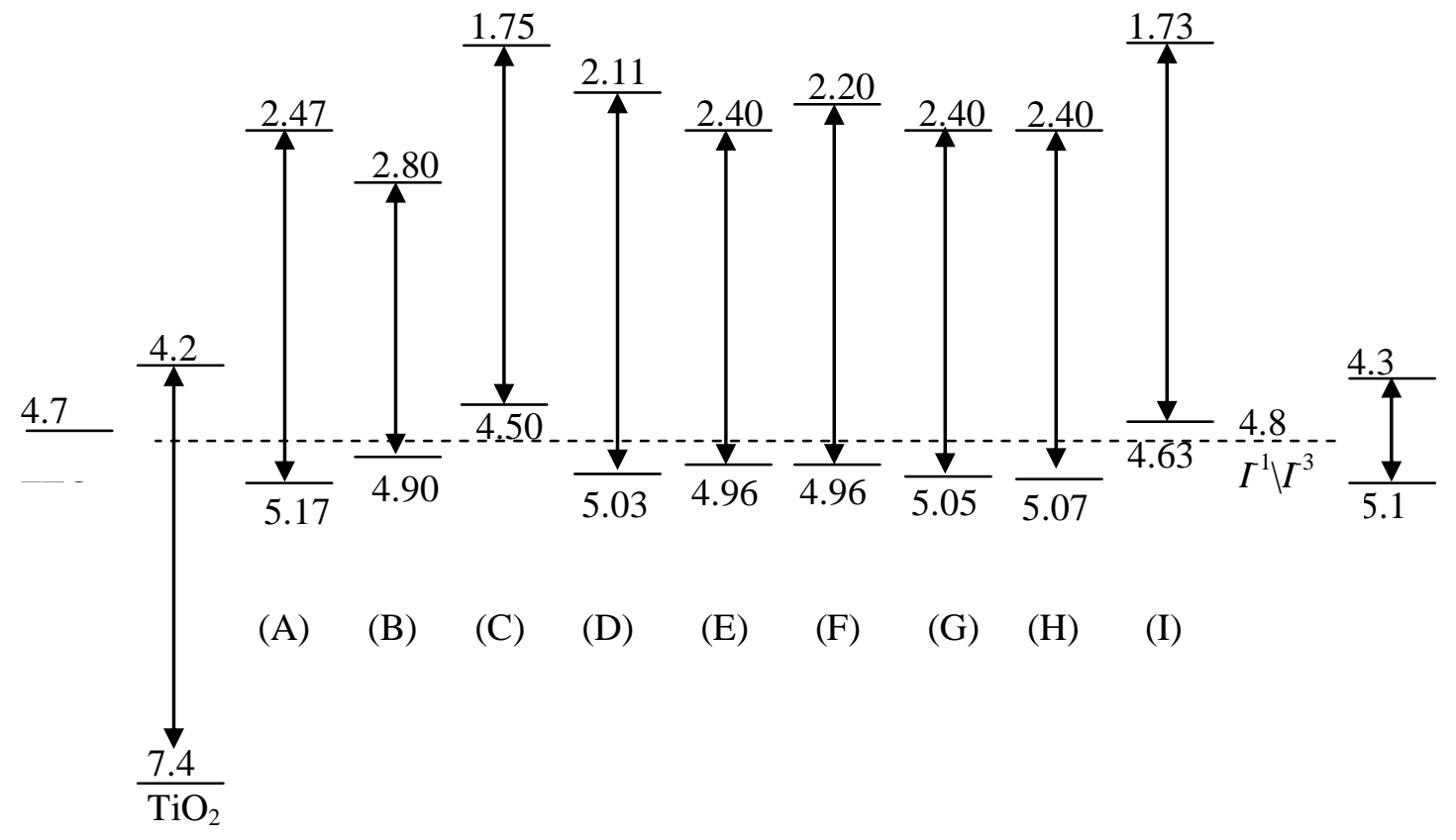

Fig. 3 - Energy (in eV) band diagram of all dyes in addition to the work function of $\mathrm{FTO}, \mathrm{TiO}_{2}, I^{-1} / I^{-3}$ and $\mathrm{Pt}$ 

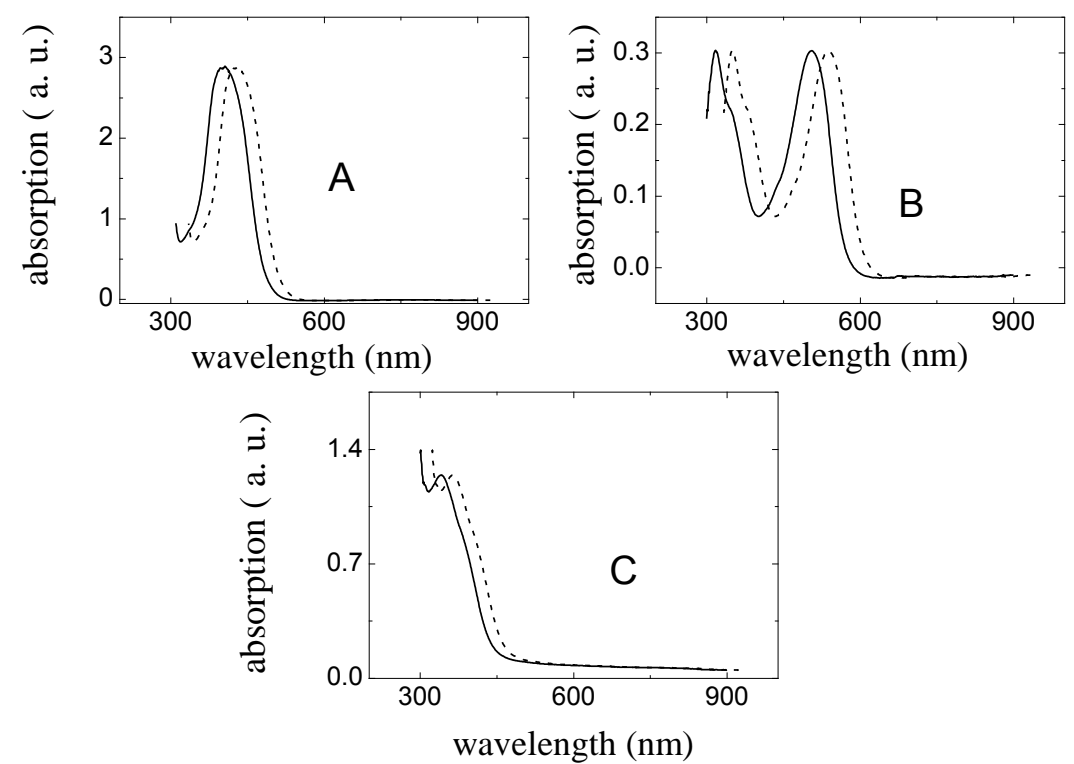

Fig. 4 - Absorption spectra of dye solutions of (A) Hy-COOH-2-AP, (B) Hy-2,6-DAP, and (C) Hy-COOH-DPA. The solid and dashed lines represent the absorption spectrum of the dye solution and that of the dye adsorbed on $\mathrm{TiO}_{2}$

Table 2 - Maximum absorption wavelength, band gap, and HOMO and LUMO levels for all dyes

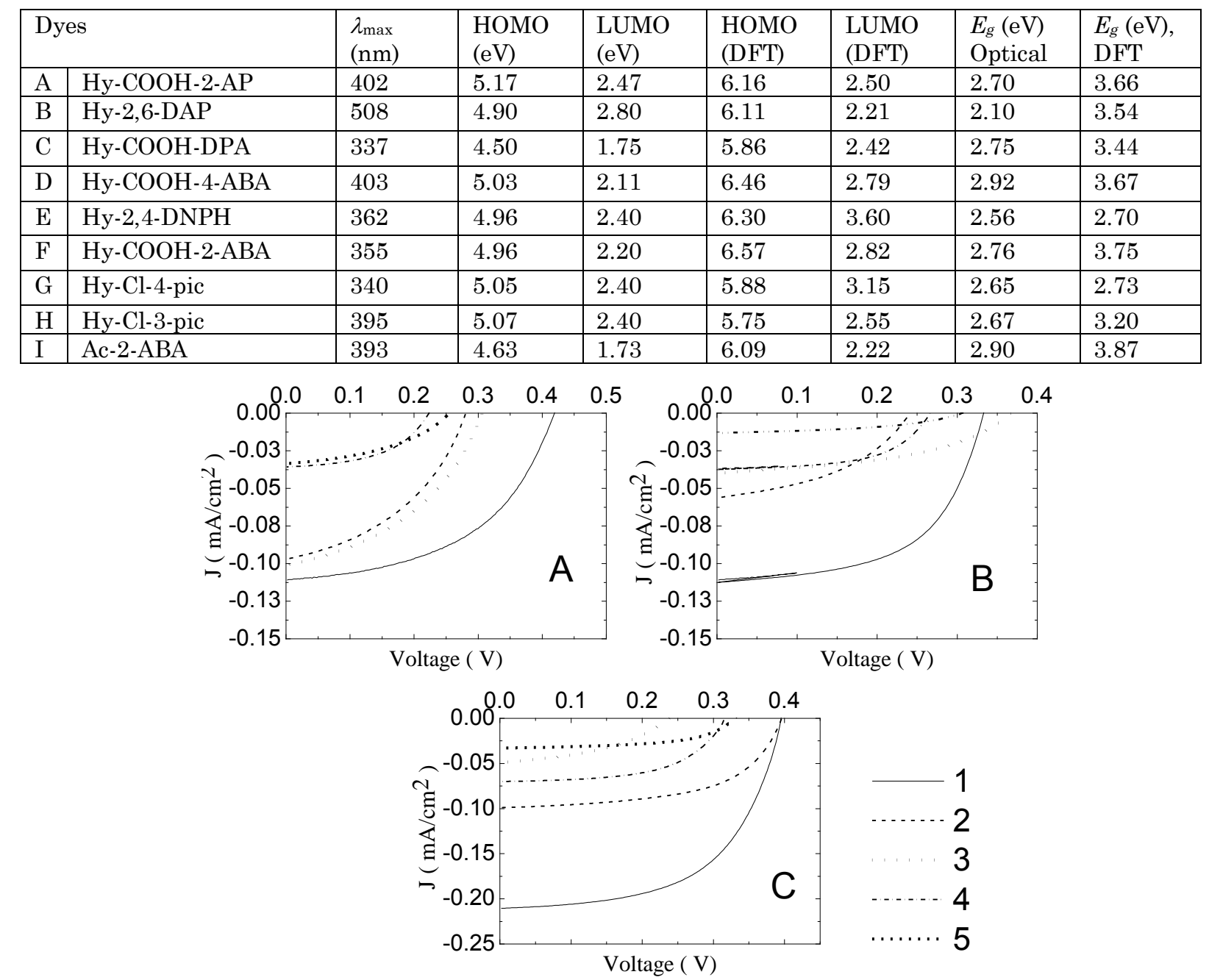

Fig. 5 - Current density-voltage curves of Hy-COOH-2-AP (A), Hy-2,6-DAP (B), and Hy-COOH-DPA (C) 
Table 3 - Photoelectrochemical parameters of the DSSCs sensitized by the three synthetic photosensitizers Hy-COOH-2-AP (A), Hy-2,6-DAP (B), Hy-COOH-DPA (C)

\begin{tabular}{|c|c|c|c|c|c|c|c|c|c|}
\hline & \multicolumn{3}{|c|}{ Hy-COOH-2-AP } & \multicolumn{3}{|c|}{ Нy-2,6-DAP } & \multicolumn{3}{|c|}{ Hy-COOH-DPA } \\
\hline & $\begin{array}{l}J s c \\
\left(\mathrm{~mA} / \mathrm{cm}^{2}\right)\end{array}$ & $\operatorname{Voc}(\mathrm{V})$ & $\eta(\%)$ & $\begin{array}{l}J s c \\
\left(\mathrm{~mA} / \mathrm{cm}^{2}\right)\end{array}$ & $\operatorname{Voc}(\mathrm{V})$ & $\eta(\%)$ & $\begin{array}{l}J s c \\
\left(\mathrm{~mA} / \mathrm{cm}^{2}\right)\end{array}$ & $\operatorname{Voc}(\mathrm{V})$ & $\eta(\%)$ \\
\hline 1 & 0.11 & 0.419 & 0.02 & 0.11 & 0.333 & 0.020 & 0.21 & 0.395 & 0.04 \\
\hline 2 & 0.10 & 0.280 & 0.01 & 0.03 & 0.367 & 0.005 & 0.10 & 0.395 & 0.01 \\
\hline 3 & 0.10 & 0.307 & 0.01 & 0.05 & 0.242 & 0.004 & 0.04 & 0.233 & 0.005 \\
\hline 4 & 0.03 & 0.220 & 0.009 & 0.03 & 0.238 & 0.003 & 0.07 & 0.313 & 0.01 \\
\hline 5 & 0.03 & 0.249 & 0.009 & 0.01 & 0.302 & 0.001 & 0.03 & 0.326 & 0.004 \\
\hline
\end{tabular}
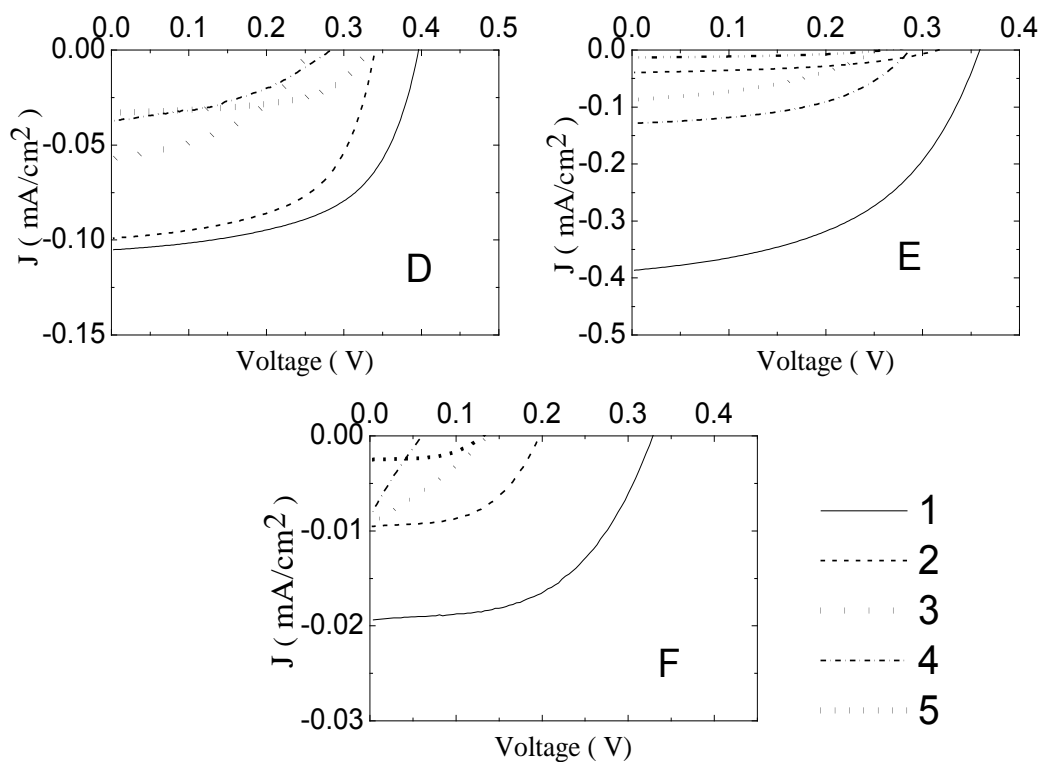

Fig. 6 - Current density-voltage curves of (D) Hy-COOH-4-ABA, (E) Hy-2,6-DNPH, and (F) Hy-COOH-2-ABA

Table 4 - Photoelectrochemical parameters of the DSSCs sensitized by the three synthetic photosensitizers (D) Hy-COOH-4-ABA, (E) Hy-2,6-DNPH, and (F) Hy-COOH-2-ABA

\begin{tabular}{|l|l|l|l|l|l|l|l|l|l|}
\hline & \multicolumn{3}{|l}{ Hy-COOH-4-ABA } & \multicolumn{3}{l|}{ Hy-2,6-DNPH } & \multicolumn{3}{l|}{ Hy-COOH-2-AB acid } \\
\cline { 2 - 10 } & $\begin{array}{l}J s c \\
\left(\mathrm{~mA} / \mathrm{cm}^{2}\right)\end{array}$ & Voc $(\mathrm{V})$ & $\eta(\%)$ & $\begin{array}{l}J s c \\
\left(\mathrm{~mA} / \mathrm{cm}^{2}\right)\end{array}$ & Voc $(\mathrm{V})$ & $\eta(\%)$ & $\begin{array}{l}\text { Jsc } \\
\left(\mathrm{mA} / \mathrm{cm}^{2}\right)\end{array}$ & $\begin{array}{l}\text { Voc } \\
(\mathrm{V})\end{array}$ & $\eta(\%)$ \\
\hline 1 & 0.10 & 0.398 & 0.02 & 0.38 & 0.360 & 0.069 & 0.02 & 0.326 & 0.003 \\
\hline 2 & 0.09 & 0.339 & 0.01 & 0.12 & 0.281 & 0.01 & 0.009 & 0.198 & 0.0008 \\
\hline 3 & 0.05 & 0.329 & 0.008 & 0.08 & 0.306 & 0.01 & 0.009 & 0.215 & 0.0008 \\
\hline 4 & 0.03 & 0.281 & 0.003 & 0.03 & 0.245 & 0.002 & 0.009 & 0.050 & 0.0005 \\
\hline 5 & 0.03 & 0.285 & 0.003 & 0.10 & 0.228 & 0.0009 & 0.002 & 0.125 & 0.0001 \\
\hline
\end{tabular}

Table 5 - Photoelectrochemical parameters of the DSSCs sensitized by the three synthetic photosensitizers (G) Hy-Cl-4-Pic, (H) Hy-Cl-3-Pic, (I) Ac-2-ABA

\begin{tabular}{|l|l|l|l|l|l|l|l|l|l|}
\hline & \multicolumn{3}{|l}{ Hy-Cl-4-Pic } & \multicolumn{2}{l|}{ Hy-Cl-3-Pic } & \multicolumn{2}{l|}{ Ac-2-ABA } \\
\cline { 2 - 11 } & $\begin{array}{l}J s c \\
\left(\mathrm{~mA} / \mathrm{cm}^{2}\right)\end{array}$ & Voc $(\mathrm{V})$ & $\eta(\%)$ & $\begin{array}{l}\text { Jsc } \\
\left(\mathrm{mA} / \mathrm{cm}^{2}\right)\end{array}$ & Voc $(\mathrm{V})$ & $\eta(\%)$ & $\begin{array}{l}J s c \\
\left(\mathrm{~mA} / \mathrm{cm}^{2}\right)\end{array}$ & $\begin{array}{l}\text { Voc } \\
(\mathrm{V})\end{array}$ & $\eta(\%)$ \\
\hline 1 & 0.23 & 0.326 & 0.03 & 0.22 & 0.377 & 0.03 & 0.02 & 0.069 & 0.0003 \\
\hline 2 & 0.06 & 0.247 & 0.004 & 0.11 & 0.377 & 0.02 & 0.006 & 0.069 & 0.0001 \\
\hline 3 & 0.06 & 0.247 & 0.004 & 0.07 & 0.247 & 0.009 & 0.04 & 0.234 & 0.002 \\
\hline 4 & 0.02 & 0.219 & 0.001 & 0.02 & 0.145 & 0.0008 & 0.01 & 0.040 & 0.00009 \\
\hline 5 & 0.002 & 0.140 & 0.00006 & 0.002 & 0.080 & 0.0004 & 0.002 & 0.040 & 0.00009 \\
\hline
\end{tabular}




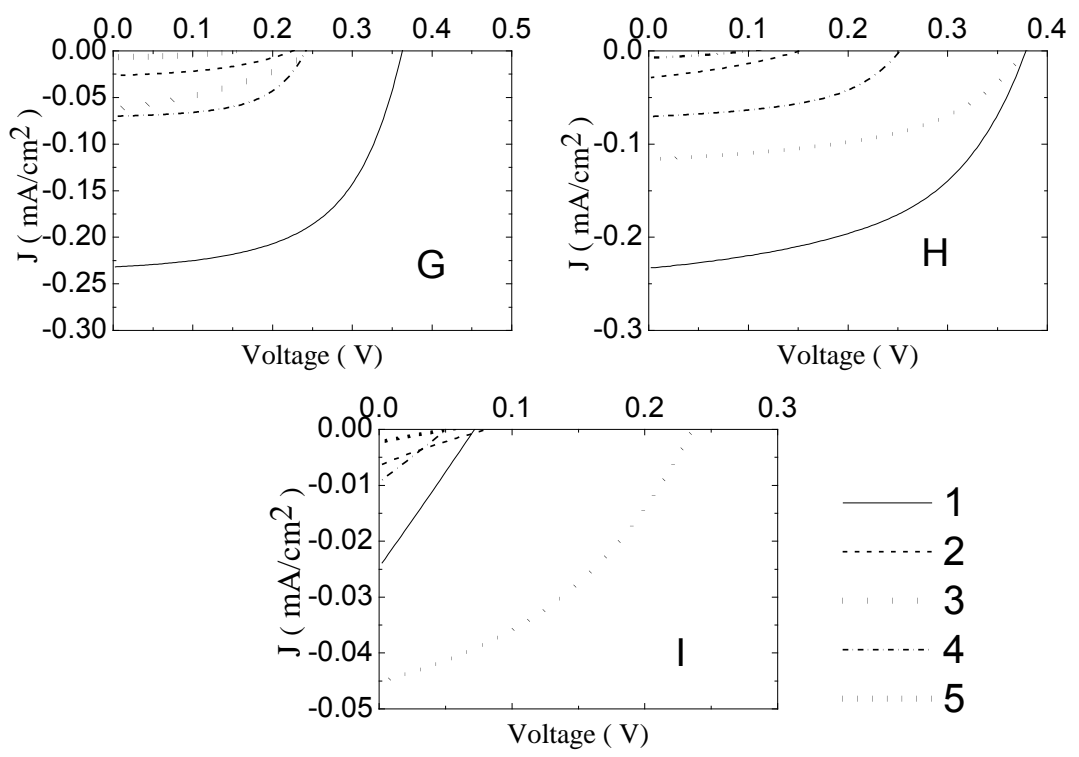

Fig. 7 - Current density-voltage curves of (G) $\mathrm{Hy}-\mathrm{Cl}-4-\mathrm{Pic}$, (H) $\mathrm{Hy}-\mathrm{Cl}-3-\mathrm{Pic}$, (I) Ac - 2 - AB - acid

a solvent with phenylhydrazine, the efficiency was $\eta=0.02 \%$ indicating $200 \%$ improvement. Dye B when used with alcohol as a solvent with phenylhydrazine attained an efficiency of $0.02 \%$. The efficiencies of the DSSCs sensitized with dyes A and B with solution 1 (alcohol as a solvent with phenylhydrazine) reached the same value of $\eta$ of $0.02 \%$ showing a significant enhancement over other solutions. On the other hand, dye $\mathrm{C}$ gave $\eta=0.01 \%$ in two cases of using water as a solvent and water with dinitrophenylhydazine. In general it is clear from Table 3 that the three synthetics (A, $\mathrm{B}$ and $\mathrm{C}$ ) gave the best performance when using alcohol as a solvent with phenylhydrazine, where dye $\mathrm{C}$ showed the highest photoelectrochemical performance with $J s c=0.21 \mathrm{~mA} / \mathrm{cm}^{2}, V o c=0.395 \mathrm{~V}$, and $\eta=0.04 \%$ which is twice the conversion efficiency of dyes A and B.

According to Table 4 dye $\mathrm{D}$ gave the values $J s c=0.09 \mathrm{~mA} / \mathrm{cm}^{2}, V o c=0.339 \mathrm{~V}, \eta=0.01 \%$ in case of using water as a solvent, and $J s c=0.1 \mathrm{~mA} / \mathrm{cm}^{2}$, $V o c=0.398 \mathrm{~V}$, and $\eta=0.02 \%$ in case of alcohol as a solvent with phenylhydrazine raising the efficiency $200 \%$ due to the improvement in Voc and fill factor. Dye E recorded similar values of $J s c, V o c$ and $\eta=0.01 \%$ when using both water only and water with phenylhydrazine as solvents, but the light harvesting efficiency jumped to $\eta=0.069 \%$ due to the considerable rise in $J s c=0.38 \mathrm{~mA} / \mathrm{cm}^{2}$ and $V o c=0.36 \mathrm{~V}$ in case of using phenylhydrazine with alcohol solvent. The DSSC sensitized with dye F displayed an efficiency of $\eta=0.003 \%$ when using alcohol as a solvent with phenylhydrazine which is comparatively low.

When inspection of the photoelectrochemical parameters of dyes $\mathrm{G}, \mathrm{H}$, and I listed in Table 5, it can be noticed that both DSSCs sensitized with dyes G and $\mathrm{H}$ gave their highest efficiency in the first case when using phenylhydrazine with alcohol solvent where $\eta=0.03 \%$. The DSSC sensitized with dye I showed a relatively low response when compared to other dyes.

\section{CONCLUSION}

In this work, nine chemical compounds were sensitized, characterized and used as photosensitizers of DSSCs. The synthetic sensitizers are based on derivatives of two structures (Fig. 1) having one or two carboxylate anchoring groups. Structure I was reacted with 2,6-diaminopyridine, 2-aminobenzoic acid, 4-aminobenzoic acid, 2-aminopyridine, 2,6dinitrophenylhydrazine, and diphenylamine. Structure II was reacted with 2-aminobenzoic acid, 2-amino-3methyl, and 2-amino-4-methylpyridine. A total of nine synthetic dyes were synthesized. These compounds were evaluated theoretically using DFT, B3LYP 6-31G. Cyclic voltammetry was used to estimate the oxidation potential and energy band diagram of the synthetic dyes. The energy of the highest occupied molecular orbital (HOMO) and the energy of lowest unoccupied molecular orbital (LUMO) were estimated. The nine dyes were then used in the fabrication of DSSCs. Each dye was used as a sensitizer in five different solutions. These solutions were alcohol with phenylhydrazine, water, water with phenylhydrazine, alcohol with 2,4-dinitrophenylhydazine, and water with 2,4-dinitrophenylhydazine. The J-V characteristic curves of the DSSCs were measured under 100 $\mathrm{mW} / \mathrm{cm}^{2}$ illuminations. The DSSC sensitized with Ac-4ABA did not show any response. In general, the best solvent for these synthetic dyes corresponding to the highest values of the conversion efficiency was alcohol with phenylhydrazine (MW=144.60 gm/mol). The highest performance with an efficiency of $0.069 \%$ was exhibited with the DSSC sensitized with Hy-2,6-DNPH dissolved in alcohol with phenylhydrazine.

\section{ACKNOWLEDGEMENT}

The authors would like to express gratitude to the ministry of higher education for the financial support of this work. 


\section{REFERENCES}

1. B. O’Regan, M. Grätzel, Nature 353 No 6346, 737 (1991).

2. M. Grätzel, Acc. Chem. Res. 42, 1788 (2009).

3. K. Kalyanasundaram M. Grätzel, Coord. Chem. Rev. 77, 347 (1998).

4. T.Y. Kim, K.H. Park, Int. J. Photoenergy 2014, ID108037 (2014).

5. N. Koumura, Z.S. Wang, S. Mori, M. Miyashita, E. Suzuki K. Hara, J. Am. Chem. Soc. 128, 14256 (2006).

6. A.Y. Batniji, R. Morjan, M.S. Abdel-Latif, T.M. El-Agez, S.A. Taya, H.S. El-Ghamri, Turk. J. Phys. 38, 86 (2014)

7. G. Calogero, A. Sinopoli, I. Citro, G. DI Marco, V. Petrov, A.M. Diniz, A.J. Parola, F. Pina, Photochem. Photobiological Sci. 12, 883 (2013).

8. S. Karthikeyan, J.Y. lee, J. Phys. Chem. A 117, 10973 (2013).

9. H. Zhou, L. Wu, Y. Gao, T. Ma, J. Photochem. Photobiology A: Chem. 219, 188 (2011).

10. E. Yamazaki, M. Murayama, N. Nishikawa, N. Hashimoto, M. Shoyama, O. Kurita, Sol. Energy 81, 512 (2007).

11. S.A. Taya, T.M. El-Agez, K.S. ElRefi, M.S. Abdel-Latif, Turk. J. Phys. 39, 24 (2015).
12. S.A. Taya, T.M. EL-Agez, H.S. EL-Ghamri, M.S. AbdelLatif, Int. J. Mater. Sci. Appl. 2, 37 (2013).

13. M.S. Abdel-Latif, T.M. El-Agez, S.A. Taya, A.Y. Batniji, H.S. El-Ghamri, Mater. Sci. Appl. 4, 516 (2013).

14. S.A. Taya, T.M. El-Agez, M.S. Abdel-Latif, H.S. ElGhamri, A.Y. Batniji, I.R. El-Sheikh, Int. J. Renewable Energy Res. 4, 384 (2014).

15. T.M. El-Agez, S.A. Taya, K.S. ElRefi, M.S. Abdel-Latif, Optica Applicata 44, 345 (2014).

16. H.S. El-Ghamri, T.M. El-Agez, S.A. Taya, M.S. AbdelLatif, A.Y. Batniji, Mater. Sci.-Poland 32 No 4, 547 (2014).

17. M.S. Abdel-Latif, M.B. Abuiriban, T.M. El-Agez, S.A. Taya, Int. J. Renewable Energy Res. 5, 294 (2015).

18. C.A. Echeverry, A. Insuasty, M.A. Herranz, A. Ortíz, R. Cotta, V. Dhas, L. Echegoyen, B. Insuasty, N. Martín, Dyes Pigment. 107, 9 (2014).

19. J.G. Chen, C.Y. Chen, S.J. Wu, J.Y. Li, C.G. Wu, K.C Ho, Sol. Energ. Mater. Sol. C. 92, 1723 (2008).

20. D.P. Hagberg, T. Edvinsson, T. Marinado, G. Boschloo, A. Hagfeldt, L. Sun, Chem. Commun. 21, 2245 (2006).

21. L. Leonat, G. Sbârcea, I.V. Brânzoi, U.P.B. Sci. Bull., Series $B$ 75, 111 (2013). 